\title{
Una crítica al régimen sobre conflictos de intereses en el derecho societario colombiano*
}

\section{Juan Antonio Gaviria*}

Resumen: Este artículo argumenta que las normas societarias colombianas sobre conflictos de intereses son ineficientes, indagando las razones de ello y proponiendo algunos cambios. En particular, se formulan cuatro críticas contra las normas actuales. Primero, que deba ser el máximo órgano social quien siempre autorice una transacción entre la sociedad y sus administradores o accionistas controlantes. Segundo, que tal autorización no sirva cuando el contrato es perjudicial para la sociedad. Tercero, que la sanción a las transacciones celebradas sin dicha autorización sea siempre la nulidad absoluta. Cuarto, que no haya excepciones legales para transacciones entre sociedades de un mismo grupo empresarial.

Palabras clave: accionistas, administradores, conflictos de intereses, nulidad, remedios, sociedades.

* Fecha de recepción: 22 de noviembre de 20I6. Fecha de aceptación: 8 de mayo de 20I7. Para citar el artículo: Gaviria, J. A., "Una crítica al régimen sobre conflictos de intereses en el derecho societario colombiano", Revista de Derecho Privado, Universidad Externado de Colombia, n. ${ }^{\circ} 32$, enero-junio de 2017, 31 7-350. DOI: https://doi.org/I0.1860I/or 234366.n32.I I

** Doctorado en Derecho por la American University, The Washington College of Law. Máster en Economía por la Universidad Eafit y en Derecho por la Universidad Externado de Colombia. Abogado de la Universidad Pontificia Bolivariana. Profesor titular de la Facultad de Derecho de la Universidad Pontificia Bolivariana, Medellín, Colombia. Miembro del Grupo de Investigaciones en Derecho de la misma universidad. Contacto: juan.gaviriag@upb.edu.co 


\section{A Case against the Legal Rules on Conflicted Interested Transactions in Colombian Corporate Law}

Aвstract: This paper contends and explains why the Colombian corporate legal rules on conflict of interest are inefficient, proposing some legal changes. In particular, this paper poses four criticisms. First, Colombian law requires that the highest corporate body shall always authorize any transaction between the legal entity and any of its managers or controlling shareholders. Second, such authorization lacks any legal effect whenever the transaction is detrimental to the company. Third, all transactions entered into without such approval are voidable. Fourth, there are no exceptions regarding transactions among companies belonging to the same entrepreneurial group.

KEY wORDS: Shareholders, managers, conflicts of interest, nullity, remedies, corporations.

Sumario: Introducción. I. La normativa colombiana. II. Exigir la aprobación de la transacción que genera un conflicto de intereses por parte del máximo órgano social genera costos de transacción innecesarios. III. La autorización del máximo órgano social, a pesar de haber generado costos de transacción, no sirve cuando el acto perjudica los intereses de la sociedad. Iv. Es ineficiente que la sanción al negocio jurídico que no haya sido autorizado por el máximo órgano social sea siempre su nulidad absoluta. v. Las normas actuales no contemplan excepciones para las transacciones entre sociedades pertenecientes a un mismo grupo empresarial. Conclusiones. Bibliografía.

\section{Introducción}

Como lo indica su título, el presente artículo se refiere a las falencias que existen tanto en las normas que regulan los conflictos de intereses ${ }^{\mathrm{I}}$ en el régimen societario colombiano como en la jurisprudencia de la Superintendencia de Sociedades que ha aplicado tales reglas. En especial, se critica que la norma actual siempre contemple como sanción jurídica para transacciones viciadas por conflictos de intereses la nulidad absoluta, la cual en ocasiones puede ser menos eficiente que otras sanciones, como el otorgamiento a la parte perjudicada de daños monetarios. Los conflictos de intereses en materia societaria (self-dealing transactions en el derecho estadounidense) suelen ser aquellos que se presentan

I No solo las normas colombianas, sino también la doctrina y la jurisprudencia usualmente utilizan el término "conflicto de interés". Con todo, este término es inexacto porque el conflicto se da al existir dos intereses contrapuestos para el administrador o accionista controlante, con lo cual la expresión correcta, que se usará en este artículo, es "conflicto de intereses". 
cuando una sociedad celebra un contrato o realiza una transacción con uno de sus administradores o con uno de sus accionistas controlantes, tal como vender activos a un precio muy bajo o comprarlos a un precio muy alto. Con todo, este artículo se enfocará en las transacciones entre una sociedad y uno de sus accionistas controlantes, y no en los negocios celebrados entre una sociedad y uno de sus administradores. Este artículo tampoco se referirá a otro tipo de conflictos de intereses, aquellos que ocurren cuando un gerente o administrador usurpa una oportunidad de negocios de la sociedad (stealing a corporate opportunity en el derecho estadounidense).

Para cumplir con el alcance descrito en el párrafo anterior, la segunda sección describe la normativa colombiana sobre los conflictos de intereses que surgen entre una sociedad y alguno de sus accionistas controlantes, mientras que las siguientes secciones desarrollan las críticas a estas reglas jurídicas, es decir: por qué exigir la aprobación de una transacción que genera un conflicto de intereses por parte del máximo órgano social genera costos de transacción innecesarios (III); por qué es ineficiente que una autorización del máximo órgano social esté viciada cuando un juez considere que el acto perjudica los intereses de la sociedad (Iv); por qué es ineficiente que la sanción al negocio jurídico que no haya sido autorizado por el máximo órgano social sea siempre su nulidad absoluta (v), y por qué es un error que las normas actuales no contemplen excepciones para las transacciones entre sociedades pertenecientes a un mismo grupo empresarial (vi). Finalmente, la última sección concluye.

\section{La normativa colombiana}

La norma aplicable al análisis legal del presente texto es el artículo 23 de la Ley 222 de 1995 , que reza:

Deberes de los administradores. Los administradores deben obrar de buena fe, con lealtad y con la diligencia de un buen hombre de negocios. Sus actuaciones se cumplirán en interés de la sociedad, teniendo en cuenta los intereses de sus asociados. En el cumplimiento de su función los administradores deberán:

7. Abstenerse de participar por sí o por interpuesta persona en interés personal o de terceros, en actividades que impliquen competencia con la sociedad o en actos respecto de los cuales exista conflicto de intereses, salvo autorización expresa de la junta de socios o asamblea general de accionistas. En estos casos, el administrador suministrará al órgano social correspondiente toda la información que sea relevante para la toma de la decisión. De la respectiva determinación deberá excluirse el voto del administrador, si fuere socio. En todo caso, la autorización 
de la junta de socios o asamblea general de accionistas sólo podrá otorgarse cuando el acto no perjudique los intereses de la sociedad.

Esta norma claramente ordena a los administradores abstenerse de participar en transacciones en las cuales tengan un conflicto de intereses, como cuando estas personas desean comprar un bien de la sociedad. El alcance de la norma, sin embargo, va más allá. En efecto, la Superintendencia de Sociedades en su jurisprudencia reciente ${ }^{2}$ ha indicado que esta norma también se aplica a transacciones en las cuales el gerente no tiene ningún conflicto de intereses, pero este sí existe para un accionista controlante 3 . De hecho, como lo dice la Superintendencia de Sociedades, esta es una situación muy común:

En el contexto de sociedades cerradas, es usual que los asociados controlantes celebren negocios jurídicos de diversa índole con la compañía en la que detentan participaciones de capital. Tales operaciones pueden incluso ser indispensables para asegurar la adecuada gestión de los negocios sociales, como ocurre cuando los mayoritarios le prestan sumas dinerarias a la compañía. También es posible, sin embargo, que los accionistas controlantes se valgan de sus tratos con la sociedad para recibir anticipadamente una porción de la plusvalía generada por el cumplimiento de la actividad social o, incluso, para apropiarse en forma irregular de activos de propiedad de la compañía. En estos casos, los accionistas que contrataron con la sociedad pueden obtener un beneficio económico personal a expensas del interés social y en detrimento de los demás asociados ${ }^{4}$.

En estas situaciones, adicionalmente, la jurisprudencia ha considerado que el representante legal, a pesar de no tener interés en la transacción, es simplemente un agente del accionista inmerso en el respectivo conflicto de intereses. Al respecto, la Superintendencia de Sociedades recuerda:

La celebración de contratos con los accionistas mayoritarios de una compañía le[s] representa un manifiesto conflicto de interés a los administradores que participaron en el respectivo negocio. En efecto, la relación de dependencia que existe entre administradores y controlantes es de suficiente entidad como para comprometer el juicio objetivo de aquellos funcionarios en el curso de una ope-

2 Se habla de jurisprudencia porque en la casuística referenciada la Superintendencia de Sociedades está actuando como juez y no como autoridad administrativa. Ver arts. i I 6 CP y 24 c. g. del p.

3 Ver, p. ej., Superintendencia de Sociedades, Sentencia 2014-801-o99, Luz Amparo Mancilla Castillo y Alfonso Bolívar Correa v. Handler S.A.S., Liliana Castillo Bautista, Omar Fernando Martínez Lozano y Edisson Emir Hernández.

4 Ibíd. Por supuesto, es criticable y no completamente ajustado a derecho el que sea un decreto y no la ley el que establezca la sanción jurídica. Ver arts. 897 a 904 c. de co. 
ración determinada. Según las explicaciones antes formuladas, este conflicto de interés se concreta, específicamente, en la potestad de los controlantes de remover a los administradores en cualquier momento. De suerte que los administradores que se propongan participar en operaciones con los asociados controlantes deberán surtir el trámite de autorización contemplado en la Ley 222 de I995 y el Decreto I 925 de 2009 para los conflictos de interés 5 .

De otro lado, téngase en cuenta que el artículo 23 de la Ley 222 de 1995 no determina cuál es la sanción jurídica cuando un acto que genera conflictos de intereses no cuente con la aprobación expresa del máximo órgano social. Es el artículo 2.2.2.3.5 del Decreto I074 de 2015 (antiguo art. 5 Dcto. I92 5 de 2009), reglamentario de la anterior norma, el que establece que en tales casos la sanción aplicable es la nulidad absoluta ${ }^{6}$. Este artículo señala:

El proceso judicial para obtener la declaratoria de nulidad absoluta de los actos ejecutados en contra de los deberes de los administradores consagrados en el numeral $7 .^{\circ}$ del artículo 23 de la Ley 222 de I995, se adelantará mediante el proceso legalmente establecido, de conformidad con el artículo 233 de la Ley 222 de I995; sin perjuicio de otros mecanismos de solución de conflictos establecidos en los estatutos. Salvo los derechos de terceros que hayan obrado de buena fe7,

5 Ibíd.

6 Ver ibíd., caso en el cual la Superintendencia de Sociedades decretó la nulidad de la venta de activos sociales hecha por el liquidador a una tercera sociedad (Fanber) por un precio muy inferior al de mercado.

7 A propósito de terceros, es bienvenido que la ley proteja a los terceros de buena fe, a pesar de que ello sea contradictorio con el régimen de nulidad del código civil. Ver art. I 748 c. c. En muchos casos, con todo, tales terceros no existirán (p. ej., contratos de mutuo, de prestación de servicios, de arrendamiento de local comercial o, incluso, de compraventa de un bien que no ha sido revendido por el adquirente afectado por el conflicto de intereses). Si el tercero existe, como cuando este adquiere un bien que previamente había sido comprado por un accionista o administrador de la sociedad, es razonable que se protejan sus derechos de buena fe, porque de lo contrario se castigaría injustamente a quien no tiene medios idóneos, antes de una transacción, para verificar a bajo costo si un determinado bien fue adquirido o no bajo una situación de conflicto de intereses. De hecho, si tales terceros no participan en el proceso, estos no pueden verse afectados por la decisión judicial. Ver art. 2.2.2.3.5 Dcto. IO74 de 2015. Ver también Superintendencia de Sociedades, Sentencia 20 I4-80I-50, Carlos Hakim Daccach v. Jorge Hakim Tawil, Alejandro Hakim Dow, Angélica Patricia de la Torre Gómez, José Alejandro Samper Carreño, Daniel Alfredo Materón Osorio, Jaime Cano Fernández, Luis Miguel García Peláez, José Mauricio Rodríguez Morales, Carlos Alberto Campos Murcia, Edduar Leonardo Flórez Bohórquez, Luis Fernando Amaya Mateus y Raquel Castillo González ("Aunque la celebración de las anteriores operaciones le[s] representó un claro conflicto de interés a algunos de los demandados, a la luz de los ya citados pronunciamientos emitidos por esta Superintendencia, debe insistirse en que los terceros enumerados en la tabla número i no formaron parte del presente proceso. Por tal motivo, el despacho no puede declarar la nulidad absoluta de las operaciones reseñadas, ni impartirles órdenes a los terceros antes mencionados"). Ver Superintendencia de Sociedades, Sentencia 201 5-800-059, Martha Omaira Cárdenas Castelblanco v. Omar Dionisio Cárdenas Castelblanco, Luis Bernardo Cárdenas Castelblanco y Martha Omaira Castelblanco 
declarada la nulidad, se restituirán las cosas a su estado anterior, lo que podría incluir, entre otros, el reintegro de las ganancias obtenidas con la realización de la conducta sancionada, sin perjuicio de las acciones de impugnación de las decisiones, de conformidad con lo dispuesto en el artículo r9 I y siguientes del Código de Comercio.

Antes de proseguir, es oportuno hacer dos precisiones conceptuales, tanto sobre la noción de conflicto de intereses en el ámbito societario como sobre los principios que orientan la nulidad como sanción a un negocio jurídico en los códigos de comercio y civil. En cuanto a lo primero, José María Garrido define conflictos de intereses como aquellos que se presentan "cuando un sujeto representa los intereses de dos sujetos distintos, de modo que no puede defender los intereses de uno de ellos sin perjudicar los intereses del otro" ${ }^{8}$. En este tipo de situaciones, por consiguiente, suele suceder que el sujeto inmerso en un conflicto de intereses está obligado por un contrato a defender intereses ajenos, lo cual le obliga a actuar, en una situación particular, en contra de sus propios intereses 9 . De manera similar, el Black's Law Dictionary define conflicto de intereses como una real o aparente incompatibilidad entre los intereses privados de una persona y los deberes públicos o fiduciarios de esta misma, a la vez que define el término self-dealing como la participación en una transacción que beneficia a quien la realiza y no a la persona con la que se tiene un deber fiduciario ${ }^{\mathrm{IO}}$.

En cuanto al tema de nulidad, el artículo i 740 c. c. indica que "[e]s nulo todo acto o contrato a que falta alguno de los requisitos que la ley prescribe para el valor del mismo acto o contrato según su especie y la calidad o estado de las partes"; para, acto seguido, establecer que una nulidad puede ser absoluta o relativa. A su turno, el artículo I74I c. c. establece que son nulidades absolutas, además de las de los actos y contratos de personas absolutamente incapaces, las producidas por un objeto o causa ilícita o las generadas por la omisión de algún requisito o formalidad acerca de su naturaleza que la ley ordena, mientras que todos los demás vicios dan lugar a nulidades relativas. Por su parte, el artículo 899 c. de co. señala que son nulos absolutamente los negocios jurídicos que contraríen una

de Cárdenas. Ver también Corte Suprema de Justicia, Sala de Casación Civil, sentencia del i I de marzo de 2004, M.P.: José Fernando Ramírez Gómez, exp. 7582 ("La declaratoria oficiosa de la nulidad absoluta presupone que al pleito concurran, en calidad de partes, las personas que intervinieron en la celebración o sus causahabientes, en guarda del principio general que enseña que la declaración de nulidad de un acto o contrato en su totalidad no puede pronunciarse sino con audiencia de todos los que lo celebraron").

8 Ver Garrido, J. M., "Reflexiones sobre el tratamiento de los conflictos de intereses de los administradores en el Derecho de Sociedades", Revista de la Superintendencia de Sociedades, Superintendencia de Sociedades n. ${ }^{\circ}$ IO, 2015,7 -2 I.

9 Ver ibíd.

io Ver Black's Law Dictionary, Bryan A. Garner (ed.), Nueva York, Thomson/West, 200 i. Las traducciones al español de las definiciones en inglés son propias. 
norma imperativa (que sería el caso aplicable), que tengan causa u objeto ilícito o que se hayan celebrado por persona absolutamente incapaz.

Como en el tema tratado en este artículo la nulidad se genera por no cumplir con un trámite que la ley exige, es razonable que la nulidad consagrada en el Decreto I074 de 2015 sea absoluta y no relativa, conclusión que se reafirma al tener en cuenta que la nulidad se deriva de la violación a una norma imperativa y, por lo tanto, a un posible objeto ilícito ${ }^{\text {I }}$. Esta conclusión, sin embargo, no es absoluta. Si se considera el artículo 23 de la Ley 222 de I995 como una norma imperativa de requisitos, podría argumentarse que tendría más sentido que la sanción fuese la nulidad relativa y no la absoluta ${ }^{\mathrm{I} 2}$. Una norma imperativa de requisitos, término que nuestra legislación no usa pero que la doctrina foránea ha mencionado ${ }^{13}$, es aquella que solo permite realizar válidamente un acto jurídico si se cumplen ciertas condiciones o formalidades, en contraste con una ley permisiva, esto es, aquella que le otorga a una persona la facultad de hacer o no hacer algo, ordenando a todos los demás respetar tal facultad ${ }^{\mathrm{I} 4}$. En cualquier caso, se recuerda que el autor de este artículo considera que la sanción a las transacciones viciadas por conflictos de intereses en el tema que nos ocupa no siempre debería ser la nulidad, sin importar si esta es absoluta o relativa.

Se recuerda, además, que la nulidad en Colombia es expresa, y por lo tanto debe estar consagrada explícitamente esta sanción en una norma, sin que sea posible aplicarla por analogía o por vía extensiva ${ }^{15}$, y que esta sanción al negocio jurídico se genera por defectos de formación o estructurales de un negocio jurídico al no haber cumplido con los requerimientos del ordenamiento jurídico ${ }^{\mathrm{I}}$. Para finalizar este tema, el artículo i 746 c. c. establece que una nulidad da derecho a las partes del negocio jurídico en cuestión a ser restituidas al estado en el que habrían estado si este no se hubiera celebrado y ejecutado, norma consistente con el artículo i 625 c. c. según el cual una de las formas de extinguir obligaciones es por una declaración de nulidad.

Una vez mencionadas las normas objeto de estudio en el presente trabajo (arts. 23 num. 7 Ley 222 de I 995 y 2.2.2.3.5 Dcto. IO74 de 201 5), y teniendo en

I I Ver arts. I 5 I9, I 523 y I 526 c. c.

I 2 Ver, p. ej., G. Figueroa Yáñez, El patrimonio, 2. a ed., Santiago de Chile, Jurídica de Chile, i997, 2 I I-2 i 2 y M. Otero Lathrop, Derecho procesal civil, Santiago de Chile, Jurídica de Chile, 20oo, 88.

I3 Ver ibíd.

I4 Otro ejemplo de una norma imperativa de requisitos en el derecho colombiano es el artículo 2 I 70 ("No podrá el mandatario por sí ni por interpuesta persona, comprar las cosas que el mandante le ha ordenado vender, ni vender de lo suyo al mandate lo que este le ha ordenado comprar, si no fuere con la aprobación expresa del mandante").

i 5 Ver Arrubla Paucar, J. Contratos mercantiles, Teoría general del negocio mercantil, Apuntes sobre el derecho de sociedades, I $3 \cdot{ }^{\text {a }}$, Bogotá, Legis, 20 I 2, 277-288. Ver, en general, G. Ospina Fernández y E. Ospina Acosta, Teoría general del contrato y del negocio jurídico, Bogotá, Temis, I998, 323.

I6 Ver ibíd. 
cuenta la jurisprudencia de la Superintendencia de Sociedades, a continuación se analizan cuatro críticas contra esta normativa, a saber: que siempre se requiera la autorización del máximo órgano social (II); que tal autorización no sirva cuando el acto perjudique los intereses de la sociedad (III); que la sanción jurídica siempre sea la nulidad absoluta (Iv); y, que no haya excepciones para transacciones entre empresas de un mismo grupo empresarial (v). Estas críticas se basan en la hipótesis de que una de las posibles razones para que tanto la ley como la jurisprudencia de la Superintendencia de Sociedades sean tan protectoras de los intereses de los accionistas minoritarios en el tema de conflictos de intereses, aun a riesgo de generar ineficiencias, es la inexistencia de acciones derivativas en el derecho societario colombiano, las cuales suelen permitir a todo tipo de accionistas, sin importar su porcentaje de participación, presentar una acción judicial a nombre de la sociedad de la que hacen parte y en contra de uno de sus administradores ${ }^{17}$. Luego de tales comentarios se presentan algunas conclusiones.

\section{Exigir la aprobación de la transacción que genera un conflicto de intereses por parte del máximo órgano social genera costos de transacción innecesarios}

Este trabajo sostiene que, salvo casos excepcionales, la ley debería exigir la autorización de la junta directiva, cuando tal órgano social ha sido estipulado estatutaria o legalmente, y no la aprobación de la asamblea general de accionistas. El argumento que justifica esta proposición consiste en que exigir siempre la aprobación de la asamblea general de accionistas genera elevados costos de transacción sin que existan beneficios correlativos que los justifiquen o compensen. Como se puede observar, el análisis en este punto se circunscribe a sociedades anónimas y sociedades por acciones simplificadas, ya que en las primeras siempre hay junta directiva ${ }^{\mathrm{I} 8}$ mientras que en las segundas los accionistas pueden estipular la existencia de dicho órgano social (si guardan silencio, tal junta directiva no existirá) ${ }^{19}$. En las demás sociedades, ante la imposibilidad de tener junta directiva

I7 Ver infra, Conclusiones.

I8 Realmente no es la ley sino la Superintendencia de Sociedades la que ha considerado, en su doctrina, que la junta directiva es un órgano obligatorio en las sociedades anónimas. Ver Superintendencia de Sociedades, Oficio 220-0293I4 del I9 de marzo de 2013 ("Tenemos entonces que a la luz de las disposiciones legales vigentes, la junta directiva, conformada con miembros principales y suplentes, como órgano de administración en las sociedades anónimas, es de obligatoria existencia, pues no de otra manera se puede concebir teniendo en cuenta el carácter imperativo de las normas que hacen referencia a ella"). Con todo, ninguna norma del código de comercio (arts. 434 a 439) indica que tal junta directiva siempre deba existir. Por eso al menos un autor considera que la junta directiva no es obligatoria en sociedades anónimas. Ver GaviRIA Gutiérrez, E., Apuntes sobre el derecho de sociedades, Medellín, Señal Editora, 2004, 34.

I9 Ver art. 25 de la Ley I $25^{8}$ de 2008 y Superintendencia de Sociedades, Circular Básica Jurídica, así como el Oficio 220-051693 del 26 de junio de 2012 ("Sobre el particular, me permito manifestarle en primer lugar que en la sociedad por acciones simplificada - sAs, conforme lo consa- 
o algún otro órgano social intermedio entre la representación legal y el máximo órgano social, sí es razonable o por lo menos inevitable que sea este último el que otorgue la mencionada autorización.

Antes de mencionar por qué en la mayoría de los casos la autorización la debe dar la junta directiva y no la asamblea general de accionistas, primero se hará una breve referencia a la importancia de las transacciones entre una sociedad y sus accionistas, así entre aquella y estos no exista unidad de propósito y dirección, esto es, grupo empresarial. En efecto, en compañías cerradas, especialmente si son sociedades de familia, las operaciones entre la sociedad y sus accionistas son bastante comunes y útiles, como puede ser el caso de un bien inmueble que un accionista le arrienda a la sociedad para que opere allí su establecimiento de comercio, o de un dinero que le preste a mejores tasas que las ofrecidas por una entidad financiera. Así las cosas, prohibir estas transacciones, como afortunadamente no lo hace la legislación colombiana, no tendría sentido ${ }^{20}$.

Dada la frecuencia de tales transacciones, tener siempre que solicitar la aprobación a la asamblea de accionistas puede ser un procedimiento muy engorroso, especialmente si el número de accionistas es considerable (de hecho, la norma genera un incentivo en contra de asociarse con muchas personas) o si hay conflictos entre los socios que hagan de esta asamblea un campo de batalla cada vez que se celebran reuniones extraordinarias con el fin de obtener tales autorizaciones $^{2 \mathrm{I}}$. Téngase en cuenta, adicionalmente, que la norma colombiana no hace distinciones y, por lo tanto, si bien este artículo hace énfasis en sociedades cerradas, las normas que aquí se analizan también son aplicables a sociedades cuyas acciones cotizan en bolsa. Para estas últimas, convocar a miles de accionistas y realizar una asamblea cuyo único punto del orden del día sea aprobar una transacción necesaria o incluso urgente con uno de sus administradores o accionistas puede resultar una labor logística titánica y, además, bastante costosa. En contraste, es mucho más fácil y económico reunir a la junta directiva, que

grado en la Ley I 258 de 2008 , no es obligatoria la existencia del cuerpo colegiado denominado Junta Directiva, salvo que en los estatutos se consagre el mismo").

20 Ver supra nota I. Ver también Superintendencia de Sociedades, Sentencia 20I4-800-29, Loyalty Marketing Services Colombia s.A.s. v. Shirley Natalia Ávila Barrios ("Con todo, existe consenso en torno a la idea de que las operaciones viciadas por conflictos de interés no son necesariamente contrarias al interés social. En compañías cerradas, la proscripción absoluta de operaciones con accionistas o administradores podría, incluso, ser nociva para la gestión de los negocios de la sociedad").

2 I Si bien las asambleas no presenciales serían una opción (arts.i9 y 20 Ley 222 de 1995), la logística de ellas tampoco será fácil cuando el número de accionistas sea considerable. Podría también darse el caso de que los accionistas prefieran discutir la aprobación de una transacción de forma presencial y que ello no sea fácil por vivir en diferentes ciudades. 
se congrega con mayor periodicidad y cuyo número de integrantes puede ser inferior al de accionistas ${ }^{22}$.

La aprobación de la junta directiva se haría, como sucede en el caso especial de compraventa de acciones de la sociedad por parte de los administradores ${ }^{23}$, sin tener en cuenta el voto de las partes interesadas. Por supuesto, si luego de descontar tales votos se hace imposible lograr el quórum decisorio y deliberatorio, sí podría requerirse la aprobación de la asamblea general de accionistas. Como una segunda excepción, podría pensarse en exigir la aprobación de la asamblea de accionistas, sin que sea suficiente la de la junta directiva, cuando la transacción sea muy grande, como proporción de los activos o de los ingresos de la sociedad (p. ej., más del 30\% de los primeros o del ı०\% de los segundos). Una tercera excepción, ya mencionada, existiría en el caso de aquellas sociedades que no cuentan con junta directiva, como las sociedades por acciones simplificadas en las que no se ha estipulado tal órgano social, o como en las sociedades de responsabilidad limitada. En tales casos sí sería necesaria la aprobación del máximo órgano social, ya sea este la asamblea general de accionistas o la junta de socios.

En contraste, si la sociedad tiene un único accionista, con el cual se planea realizar una transacción, no debería exigirse ninguna autorización, ni de junta directiva ni de asamblea (teniendo en cuenta que si tal trámite se exige y no se cumple, y si posteriormente la sociedad llega a tener más de un socio, uno de los nuevos accionistas podría demandar la nulidad absoluta de tal transacción, algo que va contra toda lógica jurídica y económica). Lamentablemente, la ley colombiana actual no plantea una excepción para este caso y, por lo tanto y a pesar de su clara inutilidad, la mencionada autorización también es necesaria.

De todas maneras, podrían existir algunas críticas a la propuesta aquí planteada. En efecto, podría argumentarse que es preferible que la autorización la otorgue el máximo órgano social, una asamblea en el caso de las sociedades por acciones, porque, entre otras razones: (i) la transacción objeto de análisis sería ocasional y no relacionada con el giro ordinario de los negocios, y (ii) esta función de control, que busca el interés común o social de los asociados, podría tener más sentido en una asamblea que en una junta directiva ${ }^{24}$. Tal interés común, social, societario o de la empresa se refiere, como su nombre lo sugiere, al

22 Aunque ninguna norma del código de comercio señala la periodicidad de las reuniones de una junta directiva, la Superintendencia de Sociedades considera que esta no debe ser menor a dos veces al año (Oficio 220-069753 del 25 de mayo de 2015) y, de hecho, la mayoría de juntas directivas se reúnen con mayor frecuencia.

23 Ver art. 404 c. de co.

24 Ver el artículo i 87 c. de co., cuyo numeral sexto indica, como una de las funciones del máximo órgano social, "[a]doptar, en general, todas las medidas que reclamen el cumplimiento de los estatutos y el interés común de los asociados". Ver el artículo 420 c. de co., que se refiere a las funciones de la asamblea de accionistas en el caso de la sociedad anónima y cuyo numeral sexto indica: "[a]doptar las medidas que exigiere el interés de la sociedad". 
interés general de la sociedad como un todo, que no necesariamente coincide o es equivalente a la suma de los intereses de los accionistas o $\operatorname{socios}^{2} 5$.

Si bien estas son razones jurídicas válidas, el autor de este texto no cree que sean de mayor peso que los argumentos ya expuestos, relacionados con costos de transacción, que hacen preferible que la autorización la otorgue una junta directiva y no una asamblea de accionistas. En particular, y con relación a tales críticas, se contra-argumenta que: (i) la junta directiva tiene "atribuciones suficientes para ordenar que se ejecute o celebre cualquier acto o contrato comprendido dentro del objeto social y para tomar las determinaciones necesarias en orden a que la sociedad cumpla sus fines" ${ }^{26}$, no estando limitadas estas funciones a los actos usuales o del giro ordinario de los negocios; (ii) la propia junta directiva, al tener representación de la mayoría de accionistas, también procura el interés común o social; y, (iii) la norma propuesta, de que la autorización la otorgue la junta directiva, puede ser supletiva, en el sentido de que si los accionistas consideran preferible que sea la asamblea la que otorgue tal autorización, así se consagre en los estatutos sociales. En resumen, y en adición al argumento principal sobre costos de transacción, la aprobación de transacciones que generan conflictos de intereses parece más acorde con las funciones generales de una junta directiva que de una asamblea general de accionistas ${ }^{27}$.

Con todo, las críticas no terminan allí. También se podría mencionar que la aprobación de la asamblea es especialmente importante en sociedades de capital disperso, es decir, en aquellas en las cuales los accionistas son diferentes de los administradores. Obsérvese que, en tal caso, el conflicto de intereses sería entre la sociedad y uno de sus administradores, tema fuera del alcance de este artículo $^{28}$, y no entre la sociedad y uno de sus accionistas controlantes, situación imposible de presentarse en la hipótesis analizada.

Para finalizar este acápite, téngase en cuenta que la propuesta de este artículo está en consonancia con la mayoría de legislaciones del mundo, que salvo excepciones solo exigen que sea la junta directiva, y no la asamblea de accionistas, la que apruebe una transacción afectada por un conflicto de intereses ${ }^{29}$.

25 Ver, en general, Morgestein Sánchez, W. I., "El concepto de interés social y su impacto en el derecho de sociedades colombiano", Revist@e-Mercatoria, n. ${ }^{\text {I }}$ (2), 20 I I, I-2 I .

26 Ver art. 438 c. de co.

27 Ver art. 438 c. de co. ("Salvo disposición estatutaria en contrario, se presumirá que la junta directiva tendrá atribuciones suficientes para ordenar que se ejecute o celebre cualquier acto o contrato comprendido dentro del objeto social y para tomar las determinaciones necesarias en orden a que la sociedad cumpla sus fines"). Ver art. 420.

28 Ver Introducción supra.

29 Ver Superintendencia de Sociedades, Sentencia 2014-800-29, Loyalty Marketing Services Colombia s.A.s. v. Shirley Natalia Ávila Barrios. Ver también oecD Publishing, Related Party Transactions and Minority Shareholders Rights, París, Organization for Economic Cooperation \& Development, 2O I 2, I ; W. YAN, The Role of Representatives of Minority Shareholders in the System of Corporate Governance (In the Context of Corporate Governance in the US, EU and China), Oxford, 


\section{La autorización del máximo órgano social, a pesar de haber generado costos de transacción, no sirve cuando el acto perjudica los intereses de la sociedad}

Una segunda crítica a las normas objeto del presente análisis se basa en que, según el numeral 7 del artículo 23 de la Ley 222 de 1995 y el segundo inciso del artículo 2.2.2.3.2 del Decreto ro74 de 2015 (antiguo art. 2 Dcto. I925 de 2009), "la autorización de la junta de socios o asamblea general de accionistas sólo podrá otorgarse cuando el acto no perjudique los intereses de la sociedad" ${ }^{\circ}$. Es decir, un juez puede revisar el contenido económico y anular un negocio jurídico así este haya sido aprobado por las mayorías legales y estatutarias en una asamblea de accionistas.

Esta norma es ineficiente por varias razones. Para empezar, los casos en los cuales la autorización de la asamblea no genera efectos jurídicos dependen de un criterio muy genérico: "perjudicar los intereses de la sociedad", que ni siquiera está matizado con adverbios como manifiestamente o gravemente. Además, ¿qué se entiende por tal expresión? Muy probable y lamentablemente, lo que considere el juez de turno, toda vez que ni la ley ni el decreto reglamentario precisan este concepto $^{3 \mathrm{I}}$. Tal excesiva generalidad, sobra decirlo, genera una gran incertidumbre sobre una transacción, ya que si su beneficio para la sociedad es dudoso, lo más normal en casos en los que el precio fue cuidadosa e incluso agresivamente negociado por ambas partes, pesará sobre ella una espada de Damocles que en cualquier momento podrá caer sobre la sociedad y sus accionistas ${ }^{32}$. Dicha inseguridad jurídica, a su vez, genera otras dos consecuencias indeseadas. En primer lugar, la anticipación de esta circunstancia podría motivar que los accionistas de una sociedad se abstuvieran de realizar con la sociedad negocios que puedan ser necesarios y convenientes para esta, por temor a que en un futuro tales transacciones sean anuladas. Segundo, la norma actual incentiva la conducta oportunista de los accionistas minoritarios. Piénsese en la venta de un bien inmueble cuyo precio de mercado es volátil. Si, luego de la venta, su valor de mercado ha caído,

European University Studies, 20I6, 93-I 32; K. Hopt, "Conflict of Interest, Secrecy and Insider Information of Directors, A Comparative Analysis", European Company and Financial Law Review, 20I3, I67-1 93; y HaAs, STEVEn M., "Toward a Controlling Shareholder Harbor", Virginia Law Review, n. ${ }^{\circ}$ 90, 2004, 2245-2304.

30 Ver Superintendencia de Sociedades, Sentencia 2014-800-29, Loyalty Marketing Services Colombia s.A.s. v. Shirley Natalia Ávila Barrios.

$3^{\text {I } ~ " F a i r n e s s ~ i s ~ a n ~ e l u s i v e ~ q u e s t i o n . ~ D i f f e r e n t ~ e s t i m a t e s ~ a n d ~ s t a n d a r d s ~ o f ~ v a l u a t i o n ~ a r e ~ u s u a l l y ~ a v a i l a b l e " ~}$ (¿Qué es lo justo? es una pregunta de difícil respuesta. Diferentes estándares de valoración generalmente están disponibles): S. Bainbridge, Corporation Law and Economics, Nueva York, Foundation Press, 2012, 352.

32 Un problema adicional es que el plazo de prescripción de una acción de nulidad absoluta es de diez años (art. I Ley 79I de 2002), un término mucho más largo que el de otras prescripciones de contratos mercantiles. Ver arts. I 94 y 938 c. de co. 
el accionista minoritario no demandará la transacción. Lo contrario, sin embargo, sucederá si el bien se ha valorizado mucho. En otras palabras, el demandado asume todo el riesgo del negocio, mientras que el accionista minoritario ganará con cara (cuando la venta haya sido un mal negocio para el accionista mayoritario) y con sello (cuando la venta haya sido buena para dicho accionista controlante, caso en el cual se puede demandar y anular el negocio jurídico).

Además, según la denominada regla de la discrecionalidad (Business Fudgement Rule) ${ }^{33}$, y salvo circunstancias excepcionales, los jueces no deben inmiscuirse en las decisiones económicas de la sociedad. A pesar de no existir norma expresa que la consagre, la Superintendencia de Sociedades, como juez societario, ha sido clara en afirmar que esta regla se aplica en Colombia34. La norma analizada, sin embargo, exceptúa dicha regla de la discrecionalidad al permitir tal injerencia judicial sin ni siquiera ponerle límites. Además, decidir si una transacción en particular es o no beneficiosa para una sociedad estará usualmente por fuera de los conocimientos de un juez, que deberá delegar tal labor en un perito, lo que incrementará los costos del proceso judicial, especialmente en casos complejos, que prácticamente requerirán la participación de un sofisticado banquero de inversión 35 .

En opinión del autor de este artículo, la transacción no debería ser anulable si el máximo órgano social la autorizó (cómo máximo, se podrían otorgar perjuicios). La única excepción a esta propuesta sería un caso que cumpla con el siguiente test, del cual se deberían cumplir todos sus elementos: (i) la autorización se obtuvo gracias a los votos decisivos de los accionistas interesados en la transacción ${ }^{36}$; (ii) la transacción fue manifiesta y gravemente perjudicial para la

33 Ver, en general, Bainbridge, Corporation Law and Economics, New York, Foundation Press, 20 I 2 , 270 y F. Reyes Villamizar, Derecho societario en Estados Unidos y la Unión Europea, Bogotá, Legis, $2013,223$.

34 Ver Superintendencia de Sociedades, Sentencia 20I4-800-52, Sucesión María del Pilar Luque de Schaefer v. Luque Torre Ltda. en liquidación.

35 Ver, en general, arts. 226 a 235 c. g. del p.

36 Téngase en cuenta que la normativa actual no exige excluir estos votos, por lo que cabe evaluar judicialmente la conveniencia de una transacción. Ver Superintendencia de Sociedades, Sentencia 201 5-800-059, Martha Omaira Cárdenas Castelblanco v. Omar Dionisio Cárdenas Castelblanco, Luis Bernardo Cárdenas Castelblanco y Martha Omaira Castelblanco de Cárdenas ("[E]l sistema de autorización previsto en el numeral 7 del artículo 23 no permite descontar los votos de los asociados que cuentan con un interés en el negocio sometido a consideración de la asamblea. Es posible entonces que, mediante la simple aplicación de la ley de las mayorías, el mismo accionista controlante que se propone contratar con la sociedad imparta la aprobación exigida en el numeral 7. Como ya lo ha explicado el Despacho en otras oportunidades, esta potestad del controlante podría utilizarse para convalidar la celebración de operaciones encaminadas a expropiar a los asociados minoritarios. Y es por esta razón que cobra relevancia la regla del numeral 7 , en el sentido de prohibir la autorización de operaciones que perjudiquen los intereses de la sociedad. Ciertamente, aunque la mayoría apruebe la suscripción de un contrato con los votos del controlante interesado, los minoritarios contarán con la posibilidad de alegar que la operación fue nociva para la compañía. De constatarse tal circunstancia ante las instan- 
sociedad, de tal manera que ninguna junta directiva, asamblea de accionistas o junta de socios razonable la hubiera aprobado ${ }^{37}$, y (iii) el demandante que desafía la legalidad de la transacción tiene la carga de probar (i) y (ii), carga que, por supuesto, es bastante alta. Se podría afirmar que el remedio propuesto es peor que la enfermedad descrita, puesto que el test depende de un concepto económico, el de perjuicio, que podría ser valorado con demasiada flexibilidad por el juez de turno. Sin embargo, ese riesgo se mitiga al exigir que el perjuicio sea manifiesto y grave, con lo cual solo quedan cubiertas las transacciones cuyos efectos no solo sean nefastos, sino que además podrían haber sido previstos o avizorados, con una altísima probabilidad, por cualquier órgano social razonable. Además, y según lo propuesto, el juez o árbitro que evalúe si el perjuicio es manifiesta y gravemente perjudicial debe evitar hacer análisis a posteriori, debiendo por el contrario limitarse a analizar el perjuicio de la transacción al momento en el cual esta se aprobó, sin importar los resultados posteriores debidos a los riesgos propios de los mercados y de todo negocio.

La anterior propuesta, naturalmente, es sin perjuicio de una posible responsabilidad civil e incluso penal de las personas que solicitaron o consiguieron la aprobación de la transacción en caso de que lo hayan hecho violando deberes de información o incluso mediante conductas fraudulentas. En tal escenario serían aplicables los artículos 2.2.2.3. I del Decreto IO74 de 2015 ("El administrador que incurra por sí o por interpuesta persona, en interés personal o de terceros, en conductas que impliquen conflicto de interés o competencia con la sociedad en violación de la ley y sin la debida autorización de la Asamblea General de Accionistas o Junta de Socios, responderá solidaria e ilimitadamente de los perjuicios que por dolo o culpa ocasione a los asociados, a la sociedad o a terceros perjudicados, con el propósito de lograr, de conformidad con la ley, la reparación integral") y el segundo inciso del artículo 2.2.3.3.5 ibídem ("El administrador que obre contrariando lo dispuesto en el artículo 23 de la Ley 222 de I995, será condenado a indemnizar a quien hubiese causado perjuicios. El juez competente, según lo establecido en la ley, podrá sancionar a los administradores con multas

cias judiciales, podría declararse la nulidad absoluta de las operaciones concernientes)". Ver art. 404 c. de co. (el cual, en materia de compraventa de acciones cuyo adquirente o vendedor sea un administrador, no contempla la revisión judicial de la conveniencia de la transacción).

37 Este es, en Estados Unidos, el denominado waste standard. El criterio se denomina así porque el demandante debe probar que la transacción equivale a un regalo o cuasi donación de los activos corporativos que no cumple propósito empresarial alguno. Sobra decir que, al ser este criterio bastante estricto, los casos en que los demandantes tienen éxito son mínimos. Ver BAINBRIDGE, S. M., Corporation Law and Economics, New York, Foundation Press, 20 I 2, I 54. Si se piensa que el criterio es muy ambiguo, podría exigirse, además de los requisitos ya mencionados para la obtención de la nulidad, que la transacción esté por fuera de ciertos deciles (p. ej., que no esté entre los deciles 20 y 80), de manera similar a lo que sucede en materia de precios de transferencia, materia en la cual un precio entre partes vinculadas con domicilio en diferentes países solo es aceptable tributariamente si se encuentra entre los deciles 25 y 75 . Ver arts. 260-I a 260-I I Estatuto Tributario. 
y/o con la inhabilidad para ejercer el comercio, sin perjuicio de la responsabilidad penal que dicha conducta pudiese generar"). Con todo, adviértase que estas normas requerirían el inicio de una acción social de responsabilidad que, a su vez, exige una aprobación de por lo menos la mitad más una de las acciones representadas en la reunión en la que se discuta el tema ${ }^{3}$, con lo cual posiblemente un accionista minoritario no podrá convencer al mayoritario, que estuvo de acuerdo con la transacción impugnada, de presentar tal acción.

\section{Es ineficiente que la sanción al negocio jurídico que no haya sido autorizado por el máximo órgano social sea siempre su nulidad absoluta}

Un accionista que se sienta perjudicado por un contrato celebrado entre una sociedad y uno de sus administradores o accionistas que no fue autorizado por el máximo órgano social puede solicitar la nulidad de esta transacción. Uno de los argumentos centrales de este artículo es que la nulidad es en muchos casos una sanción jurídica ineficiente, y que sería preferible que se mantuviera la transacción llevada a cabo y se decretara el pago de daños monetarios o que, al menos, el demandante pudiera elegir entre estas dos vías jurídicas.

Antes de precisar esta tesis, se recuerda que ni el artículo 23 ni ninguna otra norma de la Ley 222 de 1995 indica cuál es la sanción a una transacción afectada por un conflicto de intereses ${ }^{39}$. Es el artículo 2.2.2.3.5 del Decreto I074 de 20 I 5 (antiguo art. 5 Dcto. 1925 de 2009) el que establece: "El proceso judicial para obtener la declaratoria de nulidad absoluta de los actos ejecutados en contra de los deberes de los administradores consagrados en el numeral $7 .^{\circ}$ del artículo 23 de la Ley 222 de I995, se adelantará mediante el proceso legalmente establecido, de conformidad con el artículo 233 de la Ley 222 de I995 [proceso verbal sumario]" 40 .

Obsérvese que, realmente, la norma no está diciendo que la sanción jurídica siempre debe ser la nulidad absoluta, sino que, si la pretensión de un demandante es dicha nulidad, el camino procesal deberá ser el determinado por el artículo 233 de la Ley 222 de 1995 (proceso verbal sumario). Es decir que, en opinión del autor de este artículo, la norma obliga a que la nulidad se obtenga por este

$3^{8}$ Ver art. 25 Ley 222 de i 995 . Sobre los problemas actuales en el derecho colombiano de la acción social de responsabilidad ver, en general, Reyes Villamizar, F., Derecho societario, t. 2, Bogotá, Temis, 2017,674 .

39 Ver supra, secc. I.

40 Estas normas parecen ser imperativas, razón por la cual los estatutos sociales de una determinada sociedad no podrían pactar otro tipo de sanción. Ver también art. 233 Ley 222 de I995: "Remisión al proceso verbal sumario. Los conflictos que tengan origen en el contrato social o en la ley que lo rige, cuando no se hayan sometido a pacto arbitral o amigable composición, se sujetarán al trámite del proceso verbal sumario, salvo disposición legal en contrario". 
medio, mientras que otro tipo de sanción jurídica o de remedios, como el resarcimiento de los daños monetarios, se podrían obtener por este mismo camino o por otro procedimiento jurisdiccional. Con todo, tanto la jurisprudencia como la doctrina parecen ser pacíficas en afirmar que la nulidad siempre es la sanción jurídica que procede en el tipo de casos analizados en este artículo ${ }^{4 \mathrm{I}}$.

De una parte, la jurisprudencia de la Superintendencia de Sociedades confirma que la nulidad absoluta es siempre la sanción jurídica que procede. Por ejemplo, en el caso SAC Estructuras Metálicas S.A. v. Praxedis Fosé Daniel Correa Senior, Santiago Francisco Correa Laverde y Gloria Estella Gallo Pérez esta entidad afirmó: "A pesar de que en la Ley 222 no se le asignó una sanción expresa a la violación de lo previsto en el [...] artículo 23, la doctrina ha coincidido en que la falta de autorización a que se ha hecho referencia puede dar lugar a la nulidad absoluta de las operaciones concernientes" ${ }^{2}$. La doctrina, de otro lado, ha llegado a una conclusión similar al afirmar que "los actos celebrados en conflictos de intereses resultan absolutamente nulos"43.

Como es obvio, la declaratoria de nulidad absoluta de un contrato afectado por un conflicto de intereses implica que esta transacción nunca existió jurídicamente y que las partes de la transacción invalidada deben restituirse mutuamente las prestaciones recibidas (p. ej., el vendedor restituye el precio y el comprador el bien) 44 . A primera vista, pareciera que la declaratoria de nulidad produce efectos similares a los denominados daños de confianza (reliance damages) del derecho estadounidense ${ }^{45}$, de conformidad con los cuales la ley o un juez pone a la parte que sufre un perjuicio contractual en la situación en la que hubiera estado si el contrato no se hubiera celebrado. Tal semejanza, no obstante, solo es aparente e incluso engañosa. En efecto, en el caso de los reliance damages, estos se otorgan con ocasión de un incumplimiento de contrato, mientras que la nulidad en el caso que nos ocupa se declara por la violación de las normas sobre conflictos de intereses, caso en el cual la restitución se fundamenta de manera particular

4I Ver el artículo 830 c. de co., que consagra el pago de perjuicios en el caso del abuso del derecho, sin ordenar la nulidad de la transacción ("El que abuse de sus derechos estará obligado a indemnizar los perjuicios que cause").

42 Superintendencia de Sociedades, Sentencia 20I3-80I-35, sAc Estructuras Metálicas S.A. v. Praxedis José Daniel Correa Senior, Santiago Francisco Correa Laverde y Gloria Estella Gallo Pérez. Ver también Superintendencia de Sociedades, Oficio 220-140389 del 27 de noviembre de 2012.

43 Gil Echeverry, J. H. Derecho societario contemporáneo: Estudios de derecho comparado, Bogotá, Legis, 2012,284 .

44 Ver art. 1746 inc. 2 c. c. Ver también Corte Suprema de Justicia, Sala de Casación Civil, sentencia del 7 de marzo de I 994, M.P.: Alberto Ospina Botero, exp. 4I63 ("La sentencia de nulidad produce efectos retroactivos $\mathrm{y}$, por ende, cada parte tiene que devolver a la otra lo que ha recibido como prestación del negocio jurídico anulado, o en otros términos, las partes quedan obligadas a restituirse lo que recíprocamente se hubiesen entregado en desarrollo de la relación jurídica declarada nula”).

45 Ver art. I746 c. c. Ver Restatement (Second) of Contracts, Secc. 349. 
en el artículo i 746 c. c. y, de manera general, en el hecho de que ya no existe la causa que dio lugar a la atribución patrimonial o al negocio jurídico realizado. De hecho, en sentido estricto, y según lo establecido por el artículo i 748 c. c., una declaración de nulidad da acción reivindicatoria contra terceros poseedores de un bien, con lo cual, por lo menos desde el punto de vista puramente jurídico y dogmático, es excepcional que el artículo 2.2.2.3.5 del Decreto I074 de 2015 proteja los derechos de terceros de buena fe.

Una vez finalizada esta digresión, este artículo considera que sería más eficiente que el afectado por una transacción viciada por un conflicto de intereses no pudiera impetrar una acción de nulidad o, por lo menos, pudiera elegir entre esta y una acción puramente indemnizatoria, que podría consistir, por ejemplo, en la diferencia entre el precio al que fue vendido un bien sin obtenerse la autorización exigida por la ley y el precio de $\operatorname{mercado}^{46}$. Esta propuesta, valga la aclaración, no implica consagrar un nuevo evento que dé lugar a una lesión enorme (recordando que esta sanción debe ser excepcional)47. No sería este un nuevo caso de lesión enorme porque lo pretendido no es conjurar o reprimir un desequilibrio exagerado entre el poder de negociación de las partes de un contrato, ni tampoco rescindir un contrato, sino remediar los perjuicios que una parte pudo haber sufrido por no haber sido aprobada una transacción que generaba un conflicto de intereses por parte del máximo órgano social de una sociedad, consistiendo tales daños no en que la sociedad se hubiera privado de continuar siendo la propietaria de un bien esencial, en el caso de una compraventa, o en que se hubiera celebrado un contrato innecesario para el cumplimiento del objeto social, en el caso de otros actos jurídicos, sino en el hecho de que el precio del contrato no fue ni el de mercado ni ningún otro valor más favorable para dicha sociedad ${ }^{4}$.

De hecho, el autor de esta nota no es el primero en afirmar que la nulidad es la sanción inadecuada. En el caso Carlos Hakim Daccach v. Forge Hakim Tawily otros, los demandados esgrimieron un argumento en tal sentido, aunque este no fue aceptado por la Superintendencia de Sociedades, quien afirmó:

Aunque los apoderados de los demandados consideran que tal violación debería dar lugar a consecuencias diferentes de la nulidad reseñada, lo cierto es que existen suficientes argumentos para sostener que esta última es la sanción que proce-

46 El artículo 2.2.2.3.5 del Decreto I074 de 2015 (antiguo art. 5 Dcto. I925 de 2009), además de permitir la declaratoria de nulidad absoluta, consagra una posibilidad similar al establecer que, "[s]alvo los derechos de terceros que hayan obrado de buena fe, declarada la nulidad, se restituirán las cosas a su estado anterior, lo que podría incluir, entre otros, el reintegro de las ganancias obtenidas con la realización de la conducta sancionada...”.

47 Ver Hinestrosa, F. Tratado de las obligaciones, $3 .{ }^{a}$ ed., Bogotá, Universidad Externado de Colombia, 2007, 9r6-9г7.

48 Ver, en general, ibíd. 
de bajo el ordenamiento jurídico colombiano. Así fue reconocido explícitamente en el artículo 5 del Decreto I 925 de 2009, a cuyo tenor "el proceso judicial para obtener la declaratoria de nulidad absoluta de los actos ejecutados en contra de los deberes de los administradores consagrados en el numeral 7 del artículo 23 de la Ley 222 de I995, se adelantará mediante el proceso legalmente establecido, de conformidad con el artículo 233 de la Ley 222 de I995" "49].

El que la nulidad sea la sanción inadecuada en muchos casos, siendo preferible el pago o resarcimiento de daños monetarios, se explica mediante el siguiente caso hipotético. Supóngase que una sociedad A es dueña del inmueble Z, que no es de ninguna utilidad para el cumplimiento del objeto social. Asúmase, además, que la sociedad vende este inmueble a la sociedad B, quien posee el $55 \%$ de las acciones de la compañía. B planea arrendar el inmueble, acto jurídico que sí hace parte de su actividad empresarial. El precio de venta fue de $\$ 50.000$ millones y el valor de mercado del bien, al momento de la transacción, era de \$60.000 millones. La declaratoria de nulidad de la compraventa implicará que el bien debe regresar al patrimonio de la sociedad A, la que no requiere ni quiere dicho inmueble, y que este no podrá seguir siendo propiedad de B, quien sí lo está utilizando para sus negocios. Por tal motivo, es posible que después de que la compraventa se reverse, luego de los respectivos trámites notariales y de registro, y cumpliendo ya sí con el requisito de aprobación de la asamblea general de accionistas de la sociedad A, el inmueble $Z$ se vuelva a vender a B (o, si se quiere, a un tercero) $)^{5^{\circ}}$. En tal caso, a falta de una, tendremos tres transacciones de propiedad raíz, que requieren en todos los casos el trámite de escritura pública más la consiguiente inscripción en la oficina de registro de instrumentos públicos, lo que triplica los costos de la transacción original. El problema es que tales expensas las asume, en buena parte, la sociedad a la que el fallo judicial que declaró la nulidad quiso favorecer, con lo cual esta contará en el futuro con menos dividendos para distribuir a sus accionistas, incluyendo a quienes demandaron la mencionada compraventa. Además de lo anterior, todas estas transacciones pueden generar impuestos de renta o de ganancia ocasional (incluyendo retenciones en la fuente), que no siempre se recuperarán ${ }^{5}$. En una situación como esta sería más

49 Superintendencia de Sociedades, Sentencia 2014-80 -50, Carlos Hakim Daccach v. Jorge Hakim Tawil, Alejandro Hakim Dow, Angélica Patricia de la Torre Gómez, José Alejandro Samper Carreño, Daniel Alfredo Materón Osorio, Jaime Cano Fernández, Luis Miguel García Peláez, José Mauricio Rodríguez Morales, Carlos Alberto Campos Murcia, Edduar Leonardo Flórez Bohórquez, Luis Fernando Amaya Mateus y Raquel Castillo González. Obsérvese que en este caso la Superintendencia dijo cuál era la sanción jurídica aplicable (el ser), pero no opinó acerca de si habría una sanción o remedio más eficiente (el deber ser).

50 Para un caso similar, ver Superintendencia de Sociedades, Sentencia 2014-80I-229, Gina Maritza Leguizamón Barbosa v. Luz Amanda Leguizamón Barbosa, Rolando Leguizamón Barbosa e Inversiones Leguizamón Barbosa \& Cía. S. en C.

5 I Ver, p. ej., art. 300 Estatuto Tributario. 
eficiente que el juez ordenara que la sociedad B le pague a la sociedad A la diferencia entre el precio de mercado y el precio del contrato, sin perjuicio no solo de la responsabilidad legal de los administradores sino también de que se pueda ordenar el pago de alguna sanción adicional, a título de daños nominales, que desincentive en el futuro el incumplir con el deber de solicitar la debida autorización. Al fin y al cabo, ni el accionista minoritario ni la sociedad, en la mayoría de los casos, quieren tener el bien de vuelta ${ }^{52}$.

En este caso, al menos, el precio de mercado era superior al valor de la transacción. Una situación más grave ocurre cuando la transacción ha sido beneficiosa para la sociedad, es decir, cuando el precio de mercado es menor que el valor de la compraventa (en el ejemplo anterior, supóngase ahora que el precio del contrato fue el mismo, $\$ 50.000$ millones, mientras que el precio de mercado era de $\$ 40.000$ millones) y a pesar de ello uno de los accionistas minoritarios presenta una demanda alegando un posible conflicto de intereses. Si bien el acto demandado no perjudicó a la sociedad, asúmase que un accionista minoritario demanda esta transacción por venganza o con motivo de viejas rencillas que tiene con otros accionistas, sin que en tal situación le sea posible a la contraparte demostrar que hay un abuso del derecho o del ejercicio de acciones jurisdiccionales. Alternativamente, supóngase que tales rencillas no existen, pero que de todas maneras la parte demandante cree, de buena fe, que el acto fue desventajoso para la sociedad o simplemente considera, subjetivamente, que si ella hubiera sido el gerente, tal transacción no se hubiera llevado a cabo, demostrándose en el trámite que el acto sí fue provechoso para la sociedad o, también, que fue llevado a cabo con base en razones válidas. En una u otra hipótesis es probable que el proceso culmine con la declaración de nulidad absoluta por cuanto esta era una de las pretensiones del actor ${ }^{53}$.

Hasta ahora, este artículo ha mostrado cómo, en muchos casos, la nulidad absoluta de una compraventa de bienes inmuebles afectada por un conflicto de intereses es una solución menos eficiente que el otorgamiento de daños monetarios a la parte perjudicada. En el caso de bienes muebles, si bien los costos de transacción de deshacer el negocio original, y de volver a celebrarlo si este era lo que ambas partes querían, son menores que en el caso de inmuebles, al no reque-

52 Excepcionalmente, cuando el bien sea único (es decir, no haya reemplazo en el mercado) para la sociedad y esta así lo requiera, sí podría solicitarse la nulidad absoluta del negocio. Ver Ucc Sección 2-I76(I) (que consagra los daños monetarios como el remedio usual en casos de incumplimientos de contratos de compraventa, permitiendo el cumplimiento específico [specific performance] únicamente cuando el bien es único, como es el caso de los terrenos o de otros bienes que no tienen reemplazo en el mercado).

53 La Superintendencia de Sociedades ha sido clara al recordar que la ley no permite dejar de anular una transacción afectada por un conflicto de intereses por el simple hecho de que haya sido provechosa para la sociedad. Ver, p. ej., Superintendencia de Sociedades, Sentencia 2015-80o059, Martha Omaira Cárdenas Castelblanco v. Omar Dionisio Cárdenas Castelblanco, Luis Bernardo Cárdenas Castelblanco y Martha Omaira Castelblanco de Cárdenas. 
rirse en la mayoría de los casos ni escritura pública ni registro, de todas maneras tal sanción puede no tener sentido.

A su vez, otro tipo de contrato de compraventa, el de acciones, está sujeto a una regla especial, la del artículo 404 c. de co., cuyo primer inciso dispone:

Los administradores de la sociedad no podrán por sí ni por interpuesta persona, enajenar o adquirir acciones de la misma sociedad mientras estén en ejercicio de sus cargos, sino cuando se trate de operaciones ajenas a motivos de especulación y con autorización de la junta directiva, otorgada con el voto favorable de las dos terceras partes de sus miembros, excluido el del solicitante, o de la asamblea general, con el voto favorable de la mayoría ordinaria prevista en los estatutos, excluido el del solicitante.

Curiosamente, esta norma es más flexible que el rígido numeral 7 del artículo 23 de la Ley 222 de I995. Las razones para afirmar lo anterior son tres. Primero, la norma es supletiva para las sociedades por acciones simplificadas ${ }^{54}$. ¿Por qué no podría ser también el numeral 7 del artículo 23 de la Ley 222 de I 995 una norma supletiva en algunos casos? Segundo, la norma requiere la aprobación de la junta directiva y no de la asamblea general de accionistas. Tercero, si bien se requiere que la transacción no sea por motivos de especulación, no se exige que sea provechosa para la sociedad (tal vez porque los redactores del código pensaron que los jueces no tienen los elementos de juicio para evaluar a posteriori la razonabilidad de un precio). En síntesis, no parece adecuado que un tipo de contrato, el de compraventa de acciones, tenga un régimen más flexible que los demás. La solución sería flexibilizar todos estos otros, no volver más rígido aquel55.

En cuanto a otro tipo de contratos, especialmente aquellos de tracto sucesivo que implican la prestación de algún servicio, muchas veces las restituciones mutuas no son posibles o no tienen sentido. El arrendamiento de un local comercial es un primer ejemplo. La declaratoria de nulidad no es una máquina del tiempo y, por lo tanto, lo único que podría lograr es que el precio pactado inicialmente deje de tener efecto y que, en su lugar, por el uso y goce que el arrendatario ha disfrutado entre la celebración del contrato y su declaratoria de nulidad se cobre un canon razonable o de mercado, algo que sería económicamente equivalente a decretar daños de expectativa o monetarios. Además, la nulidad de este contrato puede tener otro efecto negativo para la sociedad, si esta era la arrendataria,

54 Ver art. 38 Ley I $25^{8}$ de 2008: "Las prohibiciones contenidas en los artículos I 55, I 8 5, 202, 404, 435 y 454 del Código de Comercio no se les aplicarán a las sociedades por acciones simplificadas, a menos que en los estatutos se disponga lo contrario".

55 Para casos en los cuales la Superintendencia de Sociedades ha declarado la nulidad de compraventa de acciones por no haberse obtenido la autorización exigida por el artículo 404 c. de co., ver, p. ej., sentencia 20I3-80 I-25, Francisco A. Martínez Quintero y Lucía Martínez de Kurday v. Sabajón Apolo S.A. y otros. 
a la que un accionista minoritario supuestamente estaría tratando de defender con su demanda. En efecto, la declaratoria de nulidad implicará que el contrato nunca existió y que, por lo tanto, el tiempo transcurrido no cuenta para efectos de determinar si ya se había cumplido el término mínimo de dos años para que el arrendatario tenga derecho a la renovación del contrato ${ }^{5}$. Si tal plazo no se ha cumplido, y el accionista mayoritario demandado, que también es el dueño del local comercial, quiere tomar venganza por la declaratoria de nulidad, podría negarse a seguir arrendando este bien inmueble.

Otro ejemplo es el contrato de mutuo, en el que puede ocurrir alguna de las siguientes dos situaciones. Primero, que la sociedad sea la acreedora y el accionista el deudor. En tal caso, la nulidad podría ser usualmente la sanción jurídica adecuada, ya que castiga al accionista deudor por haber sacrificado la liquidez de la compañía, que hubiera podido emplearse en mejores destinos y más afines al objeto social de la compañía, como por ejemplo compra de materia prima, obligándolo a devolver inmediatamente los dineros recibidos (en este caso, y a pesar de las diferencias jurídicas entre estas figuras, la nulidad podría tener efectos económicos similares a los de una cláusula aceleratoria). Esta afirmación, sin embargo, no es tan clara cuando la sociedad es la deudora, un escenario que puede ser común por varias razones. De una parte, usualmente será mejor que una sociedad que tiene dinero en exceso se lo preste a uno de sus accionistas, ahorrándose los márgenes financieros resultantes de que la primera invierta su liquidez en un banco y de que la segunda utilice el mismo canal para obtener un préstamo. De otro lado, puede suceder que la sociedad no tenga acceso al sistema financiero, debido a su mala calidad crediticia. Eso fue lo que ocurrió en el caso SAC Estructuras Metálicas S.A. v. Praxedis Fosé Daniel Correa Senior, Santiago Francisco Correa Laverde y Gloria Estella Gallo Pérez 57 . sac Estructuras Metálicas S.A. requería dinero con urgencia, pero ninguna entidad financiera se lo prestaba porque recién había salido de un proceso de reorganización bajo la Ley 550 de r999. Algunos de sus accionistas que también eran administradores obtuvieron un préstamo a título personal con el Banco de Bogotá y luego entregaron este dinero, también en préstamo, a la sociedad. A pesar de ser una transacción entre partes interesadas, no se obtuvo la aprobación de la asamblea de accionistas, muy posiblemente porque la prioridad era conseguir el dinero sin perder el tiempo en este trámite (recordándose que la autorización de la junta directiva

$5^{6}$ Ver art. 5i 8 c. de co.: "El empresario que a título de arrendamiento haya ocupado no menos de dos años consecutivos un inmueble con un mismo establecimiento de comercio, tendrá derecho a la renovación del contrato al vencimiento del mismo, salvo en los siguientes casos..." (resaltado nuestro). Ver también art. 520 ibíd.

57 Ver Superintendencia de Sociedades, Sentencia 20I3-80 I-35, sAc Estructuras Metálicas S.A. v. Praxedis José Daniel Correa Senior, Santiago Francisco Correa Laverde y Gloria Estella Gallo Pérez. Ver también Superintendencia de Sociedades, Sentencia 2014-800-29, Loyalty Marketing Services Colombia s.A.s. v. Shirley Natalia Ávila Barrios. 
no es suficiente). La propia Superintendencia de Sociedades reconoció que los accionistas administradores actuaron de buena fe y que la sociedad requería el dinero con urgencia, a pesar de lo cual este despacho anuló la transacción por no haberse obtenido la ya mencionada autorización. Este resultado es perjudicial para la propia sociedad en casos como el descrito ya que la obliga a devolver inmediatamente todo el capital prestado, a pesar de que puede no contar con la liquidez necesaria para ello o de que, si consigue el dinero con otro acreedor, la tasa de interés exigida puede ser mayor. En síntesis, como lo demuestran los anteriores ejemplos, el numeral 7 del artículo 23 de la Ley 222 de 1995 es una norma inflexible e ineficiente.

Este artículo concluye la presente sección con cuatro comentarios adicionales. Primero, tan poco adecuada es la nulidad absoluta como sanción a contratos afectados por conflictos de intereses como los que aquí se describen, que la Superintendencia de Sociedades, a pesar de afirmar reiteradamente que esta sanción es la que procede, ha preferido otorgar daños monetarios en al menos un caso $^{5}$. Segundo, la nulidad puede sanearse mediante una aprobación posterior a la transacción de la asamblea general de accionistas. Este procedimiento lo aprueba la Superintendencia de Sociedades 59 . Con todo, podría suceder que la nulidad se decrete o que el proceso verbal sumario inicie antes de que se ratifique la transacción. Una mejor solución sería que la ley permitiera que la asamblea general de accionistas tuviese plazo hasta el 3 I de marzo del año siguiente a la transacción para aprobarla, de manera que no haya necesidad de convocar una asamblea extraordinaria y que el trámite se pueda surtir en la asamblea ordinaria, antes de la cual un accionista minoritario no podría demandar la nulidad del negocio jurídico supuestamente afectado por un conflicto de intereses.

Tercero, la nulidad es la sanción adecuada en derecho societario cuando los perjuicios son muy difíciles de probar o de medir, o cuando realmente el deseo de la parte demandante es que las cosas vuelvan al estado en que se encontraban antes de la transacción impugnada, como es el caso de transformaciones ${ }^{60}$, esci-

$5^{8}$ Ver Superintendencia de Sociedades, Sentencia 20I4-80 I-099, Luz Amparo Mancilla Castillo y Alfonso Bolívar Correa v. Handler S.A.S., Liliana Castillo Bautista, Omar Fernando Martínez Lozano y Edisson Emir Hernández. En este caso, debido a que la sociedad estaba en liquidación, y a pesar de que se declaró la nulidad de la venta de unos activos sociales, la Superintendencia solo ordenó restituir las sumas pagadas en exceso, sin exigir el reintegro de bienes enajenados. Ver también Superintendencia de Sociedades, Sentencia 2014-800-29, Loyalty Marketing Services Colombia S.A.S. v. Shirley Natalia Ávila Barrios.

59 Ver Superintendencia de Sociedades, Sentencia 2015-800-059, Martha Omaira Cárdenas Castelblanco v. Omar Dionisio Cárdenas Castelblanco, Luis Bernardo Cárdenas Castelblanco y Martha Omaira Castelblanco de Cárdenas.

60 Ver Superintendencia de Sociedades, Sentencia 20I3-80I-29, Juan Carlos Borrero Quintero v. Lupa Jurídica s.A.s. 
siones $^{61}$, elección de junta directiva en violación de normas legales imperativas o de acuerdos de accionistas ${ }^{62}$, o elección del revisor fiscal, también en contravía de normas superiores ${ }^{63}$. La nulidad absoluta, sin embargo, no es la sanción adecuada en situaciones como las que se analizan en este escrito (transacciones entre sociedad y accionistas afectadas por conflictos de intereses) ${ }^{64}$. Lamentablemente, la Superintendencia de Sociedades dice lo contrario ${ }^{65}$. Como cuarto y último comentario, podría decirse incluso que la nulidad es aceptable cuando se trata de una transacción entre una sociedad y uno de sus administradores, pero no entre

6I Ver Superintendencia de Sociedades, Sentencia 20I4-80I-50, Carlos Hakim Daccach v. Jorge Hakim Tawil, Alejandro Hakim Dow, Angélica Patricia de la Torre Gómez, José Alejandro Samper Carreño, Daniel Alfredo Materón Osorio, Jaime Cano Fernández, Luis Miguel García Peláez, José Mauricio Rodríguez Morales, Carlos Alberto Campos Murcia, Edduar Leonardo Flórez Bohórquez, Luis Fernando Amaya Mateus y Raquel Castillo González.

62 Ver Superintendencia de Sociedades, Sentencia 2013-80 -37, Proedinsa Calle \& Cía. S. en C. v. Colegio Gimnasio Vermont Medellín S.A.

63 Ver Superintendencia de Sociedades, Sentencia 20I3-80 - I8, Hernando José Vergara Támara v. Hernando Vergara Támara y Cía. Ltda.

64 La nulidad también se ha decretado, erróneamente, en casos basados en normas diferentes al numeral 7 del artículo 23 de la Ley 222 de I995. El mejor ejemplo es la Sentencia 20I4-80II 36 de la Superintendencia de Sociedades, Martha Cecilia López v. Comercializadora g.L. s.A.s., Luis Enrique Gil Builes y Distribuidora del Kamino S.A.S. En este caso, la demandante, dueña del $40 \%$ de las acciones, alegaba que Luis Enrique Gil Builes, propietario del 60\% de las acciones, había abusado de su derecho al voto (art. 43 Ley I 258 de 2008 ) al votar favorablemente y así aprobar una enajenación global de activos y pasivos de la sociedad Comercializadora G.L. S.A.s. en favor de una sociedad que era enteramente de su propiedad, Distribuidora del Kamino s.A.s. Debido a que el patrimonio de la sociedad Comercializadora G.L. s.A.s. era negativo, tal cesión de activos y pasivos se hizo a título gratuito. La Superintendencia anuló la transacción considerando que la valoración de los activos cedidos (el terreno donde funcionaba una estación de gasolina más los activos necesarios para la venta de combustible) debía haberse hecho mediante el método de flujos de caja libre descontados. La decisión es desconcertante, no solo porque el patrimonio negativo de la sociedad indicaba que la empresa ya no estaba realmente en marcha, sino también porque: (i) no hay ninguna norma que obligue en tal caso a una valoración por el método de flujos de caja libre descontados; (ii) en caso de que tal norma existiera, el despacho podía haber ordenado esta prueba; y, más grave aún, (iii) la Superintendencia, al ordenar reversar los activos a la sociedad original, en vez de cumplir su función de resolver una disputa, perpetuó el conflicto entre los dos accionistas. Una mejor sanción que la nulidad hubiera sido otorgar daños monetarios a la demandante (medidos, p. ej., como la diferencia entre la valoración de los activos enajenados mediante el método de flujos de caja libre descontados y el valor de la cesión, que, al ser gratuita, fue de cero). Un caso similar es la sentencia 2014-80052, Sucesión María del Pilar Luque de Schaefer v. Luque Torre Ltda. en liquidación, en la cual la Superintendencia declaró la nulidad absoluta de la venta de un inmueble durante el proceso de liquidación de la sociedad, al no tener relación directa con la liquidación. Recordando que el artículo 223 c. de co. no indica necesariamente que la nulidad sea la sanción jurídica aplicable en casos como este, no parece adecuado que el bien regrese a una sociedad que no lo requiere, y sería preferible condenar monetariamente al demandado por la diferencia en precios.

65 Ver Superintendencia de Sociedades, Sentencia 20 I 2-80 I-029, Capital Airports Holding Company v. САн Colombia S.A. (“[L]a simple indemnización de perjuicios que puede reclamarse por virtud de esta norma es insuficiente para resolver conflictos de Derecho de Sociedades”). 
una sociedad y uno de sus accionistas, caso en el cual el régimen legal debería ser más flexible ${ }^{66}$.

\section{Las normas actuales no contemplan excepciones para las transacciones entre sociedades pertenecientes a un mismo grupo empresarial}

Sin perjuicio de lo ya afirmado en las secciones previas de este artículo, las reglas sobre conflictos de intereses deberían flexibilizarse cuando las operaciones se realizan entre compañías pertenecientes a un mismo grupo empresarial. En tal caso y para la protección de los accionistas minoritarios, son más que suficientes dos normas que ya existen. De una parte, la norma internacional de contabilidad IAS 24 sobre transacciones entre partes vinculadas, que ya está vigente en Colombia ${ }^{6}$. De otro lado, el artículo 265 c. de co., modificado por el artículo 3 I de la Ley 222 de 1995 , según el cual:

Los respectivos organismos de inspección, vigilancia o control, podrán comprobar la realidad de las operaciones que se celebren entre una sociedad y sus vinculados. En caso de verificar la realidad de tales operaciones o su celebración en condiciones considerablemente diferentes a las normales del mercado, en perjuicio del Estado, de los socios o de terceros, impondrán multas y si lo considera $[s i c]$ necesario, ordenarán la suspensión de tales operaciones. Lo anterior, sin perjuicio de las acciones de socios y terceros a que haya lugar para la obtención de las indemnizaciones correspondientes.

Por cierto, obsérvese que esta norma, a diferencia del numeral 7 del artículo 23 de la Ley 222 de I995, no exige aprobaciones especiales por parte de órganos societarios ni tampoco consagra como sanción la nulidad (en vez de ella, la norma utiliza el término "indemnizaciones").

Lamentablemente, no solo esas normas sino también el ya analizado numeral 7 del artículo 23 son aplicables en tratándose de transacciones entre compañías vinculadas. Nuevamente se afirma: esta norma es demasiado rígida. La propia Superintendencia de Sociedades reconoce la funcionalidad económica de las transacciones intra grupo, recordando que generan mercados internos,

66 Así sucede en Estados Unidos, donde los jueces son más flexibles al analizar las transacciones con accionistas que con los gerentes, bajo el raciocinio de que los primeros tienen interés en el resultado de la sociedad. Ver Bainbridge, Corporation Law and Economics, cit., 345.

67 Ver, en general, Ley I3 14 de 2009. 
sinergias y ahorros en costos al evitar, por ejemplo, intermediación de terceros como proveedores o bancos ${ }^{68}$.

Por ello, este escrito argumenta que la ley debería expresamente exceptuar la aplicación de dicha norma en los siguientes supuestos: (i) cuando la matriz es la dueña del cien por ciento de las acciones de la sociedad filial, caso en el cual la autorización de la asamblea de "accionistas" representa un trámite innecesario que solo consume tiempo valioso de los accionistas y administradores (lo propio sucede si hay más de una sociedad accionista pero todas ellas pertenecen a un mismo beneficiario real); y (ii) en las transacciones de rutina o que pertenecen al giro ordinario de los negocios de la sociedad, como giros de dinero repetitivos o ventas de inventario, que no deberían requerir ningún tipo de aprobación, como usualmente sucede en otros países ${ }^{69}$.

\section{Conclusiones}

Nadie desconoce que la protección a los accionistas minoritarios es necesaria, especialmente en el caso de sociedades cerradas, es decir, aquellas que no han emitido acciones u otro tipo de instrumentos financieros en el mercado público de valores ${ }^{70}$. Así, nadie quiere regresar a las épocas en las que los accionistas mayoritarios expropiaban o violaban impunemente de sus asociados minoritarios. Tampoco se niega la necesidad de implementar controles legales a las operaciones entre la sociedad y sus administradores o accionistas. Con todo, parece que con el ánimo de corregir situaciones inadecuadas del pasado hemos exagerado la dosis del remedio y virado hasta el otro extremo del péndulo. En efecto, y al menos en el tema de este artículo, el de los conflictos de intereses, pareciera haber un sesgo tanto en la ley como en la jurisprudencia, consistente en una excesiva protección a favor de los accionistas minoritarios. Este sesgo, por ejemplo, lo comprueba el que la propia Superintendencia de Sociedades recuerde (resaltado nuestro) que "siempre que una compañía pretenda celebrar operaciones con su accionista controlante o con sociedades controladas por ese mismo sujeto, deberá surtirse el trámite previsto en el numeral 7 del artículo 23 de la Ley 222 de 1995 (autorización de la asamblea general de accionistas o de la junta de socios)"7I.

68 Ver Superintendencia de Sociedades, Sentencia 20I4-800-29, Loyalty Marketing Services Colombia S.A.S. v. Shirley Natalia Ávila Barrios.

69 Ver, p. ej., Francia, art. L. 223-I9 SARL y L.225-40 y 225-88 (SA) c. de co., así como la denominada doctrina Rozenblum. Ver también oecd Publishing, Related Party Transactions and Minority Shareholders Rights, París, Organization for Economic Cooperation \& Development, 20 I 2, I 2.

70 Ver, en general, Ley 964 de 2005.

7I Superintendencia de Sociedades, Sentencia 2014-80I-099, Luz Amparo Mancilla Castillo y Alfonso Bolívar Correa v. Handler S.A.S., Liliana Castillo Bautista, Omar Fernando Martínez Lozano y Edisson Emir Hernández. 
El que las normas actuales sobre conflictos de intereses sean excesivamente protectoras de los accionistas minoritarios genera al menos dos problemas. De una parte, se frenan transacciones entre una sociedad y sus accionistas (e.g., otras sociedades) que pueden ser provechosas para ambas partes o incluso indispensables $^{72}$. De otro lado, se puede estar creando un derecho de veto o, incluso, un incentivo para que los accionistas minoritarios se comporten de manera oportunista, al demandar una transacción que fue beneficiosa para la sociedad simplemente por desatar un conflicto con los accionistas mayoritarios, con ánimo de revancha por posibles decisiones del pasado, o por ignorancia. Antes que soluciones de extremo, la ley debe abogar por hallar el justo medio. En palabras del juez Frank Easterbrook y del profesor Daniel R. Fischer, las normas societarias, de un lado, deben otorgar cierta protección a los inversionistas minoritarios para asegurar que estos reciban un retorno adecuado sobre su inversión si el negocio es exitoso; de otro lado, tales normas no pueden otorgar demasiados derechos, ya que la minoría los puede ejercer de manera oportunista con el fin de desviar resultados 73 .

¿Cuál es la razón de que no solo la ley sino también la jurisprudencia de la Superintendencia de Sociedades otorguen tanta protección a los accionistas minoritarios en materia de operaciones afectadas por conflictos de intereses, a pesar de que tales normas y decisiones tienen efectos nocivos para la propia sociedad, y por consiguiente para todos sus accionistas, en el largo plazo, al desestimular transacciones provechosas? La explicación del autor de este artículo se presenta en los siguientes párrafos.

De una parte, en Colombia no existe la denominada acción derivativa (derivative suit), mediante la cual un accionista, así sea minoritario, puede presentar una acción a nombre de la sociedad de la que hace parte y en contra de uno de sus administradores ${ }^{74}$. De otro lado, la ley colombiana sí consagra una acción

72 Ver Superintendencia de Sociedades, Sentencia 20I4-80I-50, Carlos Hakim Daccach v. Jorge Hakim Tawil, Alejandro Hakim Dow, Angélica Patricia de la Torre Gómez, José Alejandro Samper Carreño, Daniel Alfredo Materón Osorio, Jaime Cano Fernández, Luis Miguel García Peláez, José Mauricio Rodríguez Morales, Carlos Alberto Campos Murcia, Edduar Leonardo Flórez Bohórquez, Luis Fernando Amaya Mateus y Raquel Castillo González.

73 La cita textual es: "On the one hand, they must provide some protection to minority investors to ensure that they receive an adequate return on the minority shareholder's investment if the venture succeeds. On the other hand, they cannot give the minority too many rights, for the minority might exercise their rights in an opportunistic fashion to divert results": F. Easterbrok y D. Fischer, The Economic Structure of Corporate Law, Cambridge, Harvard University Press, I996, 238.

74 Ver art. 24 Ley 222 de I995; Superintendencia de Sociedades, Sentencia 20 I4-80 I-50, Carlos Hakim Daccach v. Jorge Hakim Tawil, Alejandro Hakim Dow, Angélica Patricia de la Torre Gómez, José Alejandro Samper Carreño, Daniel Alfredo Materón Osorio, Jaime Cano Fernández, Luis Miguel García Peláez, José Mauricio Rodríguez Morales, Carlos Alberto Campos Murcia, Edduar Leonardo Flórez Bohórquez, Luis Fernando Amaya Mateus y Raquel Castillo González; y Superintendencia de Sociedades, Sentencia 2015-800-059, Martha Omaira Cárdenas Castelblanco v. Omar Dionisio Cárdenas Castelblanco, Luis Bernardo Cárdenas Castelblanco y Martha Omaira Castelblanco de Cárdenas (casos en los que la Superintendencia reconoce 
social de responsabilidad que pueden interponer los accionistas en contra de los administradores75. Con todo, el que la ley exija que esta acción solo se pueda interponer si tal decisión ha sido aprobada por la mayoría de votos del máximo órgano social ${ }^{6}$, aunado al hecho de que el administrador a quien se quiere demandar es frecuentemente uno de los accionistas controlantes, o un aliado de estos, ha hecho que pocas veces un accionista minoritario tenga éxito en la interposición de una acción social de responsabilidad, tal como lo ha reconocido la propia Superintendencia de Sociedades ${ }^{77}$.

Estimamos, por lo tanto, que la ausencia de una acción derivativa, aunada a la poca efectividad de la acción social de responsabilidad en Colombia, y al deseo de compensar los perjuicios que pueden sufrir los accionistas minoritarios por tener cerradas estas dos vías procesales, ha llevado a que la Superintendencia de Sociedades, como juez societario, solucione un mal con otro mal al extender indebidamente el alcance de la protección de los accionistas minoritarios. Para

que tal acción no existe en el derecho colombiano). Ver también J. Suescún Melo, Estudios de derecho privado, t. II, Bogotá, Cámara de Comercio de Bogotá y Universidad de los Andes, I996, 320. En contraste, esta acción sí existe tanto en el Reino Unido, donde se originó (ver el célebre caso Foss v. Harbottle (1843) 67 ER I 89; ver también Boyle, A. J., Minority Shareholders' Remedies, Cambridge, Cambridge University Press, 2002, I), como en Estados Unidos (ver Cabrelli, D., Shareholders' Rights and Litigation, en Siems, M. y Cabrelli, D. (coords.), Comparative Company Law: A Case-Based Approach, Oxford, Hart Publishing, 2013, 287-326). En cuanto a Europa continental, este tipo de acciones también son permitidas, aunque se suele exigir un mínimo de participación accionaria al accionista que presenta la demanda (p. ej., $5 \%$ en Francia y io\% en Alemania. Ver ibíd.

75 Ver arts. 24 (que modificó el art. 200 c. de co.) y 25 Ley 222 de 1995.

76 Ver art. 25 Ley 222 de 1995 : "Acción social de responsabilidad. La acción social de responsabilidad contra los administradores corresponde a la compañía, previa decisión de la asamblea general o de la junta de socios, que podrá ser adoptada aunque no conste en el orden del día. En este caso, la convocatoria podrá realizarse por un número de socios que represente por lo menos el veinte por ciento de las acciones, cuotas o partes de interés en que se halle dividido el capital social. La decisión se tomará por la mitad más una de las acciones, cuotas o partes de interés representadas en la reunión e implicará la remoción del administrador".

77 Ver, p. ej., Superintendencia de Sociedades, Sentencia 20I4-80I-I64, Jorge Eduardo Terrero Wilches v. Rafael Uribe Toro ("Para este Despacho es claro, sin embargo, que la acción social de responsabilidad es de escasa utilidad en hipótesis de expropiación de minoritarios. Cuando el controlante ha distraído bienes de la compañía en su calidad de administrador o con el concurso de los administradores, será virtualmente imposible que se apruebe una acción social de responsabilidad en la asamblea general de accionistas. En verdad, conforme a la ley de las mayorías, la decisión de presentar la acción social dependerá del voto del mismo controlante que se lucró por virtud de la expropiación de la minoría. Parece entonces poco probable que el controlante decida tramitar un proceso judicial en contra de sí mismo o de las personas que le permitieron apropiarse de recursos sociales en forma irregular"). Con todo, la Superintendencia ha sancionado a accionistas mayoritarios que han abusado de su derecho al voto al dilatar la decisión de interponer una acción social de responsabilidad o al votar en contra de ella sin la debida argumentación. Ver, p. ej., Superintendencia de Sociedades, Sentencia 20 14-80 I- - 66, Jovalco s.A.s. v. Construcciones Orbi S.A. ("Resuelve. Primero. Declarar la nulidad del voto emitido por Construcciones Orbi S.A. en contra de la propuesta de iniciar una acción social de responsabilidad, durante la reunión extraordinaria de la junta de socios de Sares Ltda. celebrada el I3 de abril de 2013"). 
dar una ilustración, en el caso Carlos Hakim Daccach v. Forge Hakim Tawily otros se recordó que "este Despacho ha puesto de presente que a pesar de los problemas de la acción social, los accionistas minoritarios expropiados cuentan con diferentes vías judiciales para defender sus intereses" 78 . Estas otras vías judiciales son la acción por abuso de mayoría al votar (art. 43 Ley I 258 de 2008), la acción por abuso del derecho (art. 830 c. de co.) y, la que nos interesa para este artículo, la acción de nulidad por violación del régimen de conflictos de intereses (art. 23 num. 7 Ley 222 de I995).

Para terminar, se proponen algunas reformas a la normativa actual. Primero, se propone flexibilizar las reglas aplicables a transacciones entre empresas pertenecientes a un mismo grupo empresarial, caso en el cual no se debería exigir aprobación si el contrato hace parte del giro ordinario de los negocios de las sociedades participantes. La segunda recomendación es que, salvo que tal órgano no exista o que sea imposible lograr una mayoría sin contar con los votos de las partes interesadas, bastará la aprobación de la junta directiva. Asumiendo que esta propuesta no se acepte, se propone que, por lo menos, la aprobación de la asamblea pueda darse hasta el 3 I de marzo del año siguiente a la respectiva transacción y sin que en el interregno se pueda demandar tal negocio jurídico, y que, una vez obtenida tal aprobación, nunca se pueda evaluar judicialmente si el contrato celebrado era o no beneficioso para la sociedad. Después de todo, y en virtud de la regla de la discrecionalidad, los jueces no deben revisar a posteriori las decisiones económicas de una sociedad (además de que carecen de los conocimientos y la experiencia para hacerlo) ${ }^{79}$.

Tercero, se propone modificar la reglamentación actual (Dcto. I074 de 20 I 5 , anteriormente Dcto. I92 5 de 2009) de tal manera que quede expresamente claro que la sanción al acto jurídico no siempre será la nulidad ${ }^{80}$. Así las cosas, se permitiría al demandante elegir entre solicitar la nulidad absoluta de la transacción o, en su defecto, pedir daños monetarios. En todo caso, si solicita la nulidad, debe argumentar exitosamente por qué esta es la sanción adecuada y, en caso de no hacerlo, el juez podría otorgar daños monetarios. Tal como se mencionó

78 Superintendencia de Sociedades, Sentencia 20 I4-80 -50, Carlos Hakim Daccach v. Jorge Hakim Tawil, Alejandro Hakim Dow, Angélica Patricia de la Torre Gómez, José Alejandro Samper Carreño, Daniel Alfredo Materón Osorio, Jaime Cano Fernández, Luis Miguel García Peláez, José Mauricio Rodríguez Morales, Carlos Alberto Campos Murcia, Edduar Leonardo Flórez Bohórquez, Luis Fernando Amaya Mateus y Raquel Castillo González.

79 Ver Delaware General Corporation Law, Sección I44, según la cual una transacción no es anulable si se cumple una de tres condiciones: (i) se aprueba por la mayoría de directores desinteresados luego de completa revelación de hechos, (ii) se aprueba por la asamblea con mayoría de votos luego de completa revelación de hechos, o (iii) la transacción es favorable para la sociedad en el momento en que se realiza.

80 Recuérdese que, según el numeral I del artículo 899 c. de co., la sanción por violación de norma imperativa es la nulidad absoluta, salvo que la ley disponga otra cosa. En este caso, la norma que modifique el Decreto I074 de 2015 (anteriormente el Dcto. 1925 de 2009) dispondría otro tipo de sanción. 
anteriormente, otorgar daños de expectativa o monetarios puede ser un remedio más eficiente que la nulidad. De hecho, así lo considera la ley mercantil colombiana en por lo menos otros dos casos, en los cuales se prefiere la modificación del contrato, no a la nulidad, pero sí a su terminación: (i) el artículo 2 I de la Ley i I 6 de 2006, según el cual "El deudor admitido a un trámite de reorganización podrá buscar la renegociación, de mutuo acuerdo, de los contratos de acuerdo, el deudor podrá solicitar al juez del concurso, autorización para la terminación del contrato respectivo..."; y, (ii) el artículo 868 c. de co., que, al regular la denominada teoría de la imprevisión (existencia de circunstancias extraordinarias, imprevistas o imprevisibles, posteriores a la celebración de un contrato de ejecución sucesiva, periódica o diferida que alteren o agraven la prestación de futuro cumplimiento a cargo de una de las partes, en grado tal que le resulte excesivamente onerosa), indica que el juez deberá primero reajustar el contrato y, solo si ello no es posible, terminarlo.

Finalmente, se recuerda la importancia de buscar un punto medio en la protección a los accionistas minoritarios, no pecando por defecto, como en épocas pasadas, ni por exceso, como en la actual. Parafraseando a Frank Easterbrook y Daniel Fischer, mientras más responsables se hace a los administradores y accionistas de una sociedad, menos discreción y autonomía tienen estos para tomar decisiones. Lo contrario también es cierto: a mayor autonomía, menor responsabilidad, lo que tampoco puede ser bueno. El propósito del derecho de sociedades, en el tema analizado, es encontrar el punto medio eficiente, tarea que no es para nada fácil ${ }^{8 \mathrm{I}}$.

\section{Bibliografía}

\section{Artículos}

Garrido, J. M. "Reflexiones sobre el tratamiento de los conflictos de interese de los administradores en el derecho de sociedades", Revista de la Superintendencia de Sociedades, n. ${ }^{\circ}$ Io, 2015.

HaAs, Steven M. "Toward a controlling shareholder harbor", Virginia Law Review, n. ${ }^{\circ} 90,2004$.

Hорт, K. "Conflict of interest, secrecy and insider information of directors, A comparative analysis", European Company and Financial Law Review, 20 I 3. 
Morgestein Sánchez, W. I. "El concepto de interés social y su impacto en el derecho de sociedades colombiano", Revist@e-Mercatoria, n. ${ }^{\circ}$ Io(2),20I I, I-2 I.

\section{Libros}

Arrubla Paucar, J. Contratos mercantiles, Teoría general del negocio mercantil, i $3{ }^{a}$ ed., Bogotá, Legis, 2012.

Bainbridge, S. Corporation Law and Economics, New York, Foundation Press, $2 O I 2$.

Black's Law Dictionary, Bryan A. Garner (ed.), New York, Thomson/West, 200 I.

Boyle, A. J. Minority shareholders' remedies, Cambridge, Cambridge University Press, 2002.

Cabrelli, D. Shareholders' rights and litigation, en Siems, M. y Cabrelli, D. (coords.), Comparative Company Law: A Case-Based Approach, Oxford, Hart Publishing, 20I3.

Easterbrok F. y Fischer, D. The Economic Structure of Corporate Law, Cambridge, Harvard University Press, I996.

Figueroa Yáñez, G. El patrimonio, 2. ${ }^{a}$ ed., Santiago de Chile, Jurídica de Chile, I997, p. 2 I I-I 2.

Gaviria Gutiérrez, E. Apuntes sobre el derecho de sociedades, Medellín, Señal Editora, 2004 .

Gil Echeverry, J. H. Derecho societario contemporáneo: Estudios de derecho comparado, Bogotá, Legis, 2012.

Hinestrosa, F. Tratado de las obligaciones, $3 \cdot{ }^{a}$ ed., Bogotá, Universidad Externado de Colombia, 2007.

oecD Publishing, Related Party Transactions and Minority Shareholders Rights, Paris, Organization for Economic Cooperation \& Development, 20 I 2.

Ospina Fernández, G. y Ospina Acosta, E. Teoría general del contrato y del negocio jurídico, Bogotá, Temis, I 998. 
Otero Lathrop, Miguel. Derecho procesal civil, Santiago de Chile, Jurídica de Chile, 2000.

Reyes Villamizar, F. Derecho societario, t. 2, Bogotá, Temis, 20 i 7.

Reyes Villamizar, F. Derecho societario en Estados Unidos y la Unión Europea, Bogotá, Legis, 2013.

Suescún Melo, J. Estudios de derecho privado, t. iI, Bogotá, Cámara de Comercio de Bogotá y Universidad de los Andes, I996.

Yan, W. The Role of Representatives of Minority Sharebolders in the System of Corporate Governance (In the Context of Corporate Governance in the US, EU and China), Oxford, European University Studies, 2016.

\section{Jurisprudencia}

\section{Corte Suprema de Fusticia, Sala de Casación Civil}

Sentencia del i 8 de agosto de 2010, exp. I 500 I-3 I03-00I-2002-000 I6-or, M.P.: William Namén Vargas.

Sentencia del I4 de junio de 2000, exp. 5025, M.P.: Jorge Antonio Castillo Rugeles.

Sentencia del 2 de agosto de I999, exp. 4937, M.P.: José Fernando Ramírez Gómez.

Sentencia del 7 de marzo de I994, exp. 4I63, M.P.: Alberto Ospina Botero.

\section{Superintendencia de Sociedades}

Sentencia 201 5-800-059, Martha Omaira Cárdenas Castelblanco v. Omar Dionisio Cárdenas Castelblanco, Luis Bernardo Cárdenas Castelblanco y Martha Omaira Castelblanco de Cárdenas.

Sentencia 2014-80I-229, Gina Maritza Leguizamón Barbosa v. Luz Amanda Leguizamón Barbosa, Rolando Leguizamón Barbosa e Inversiones Leguizamón Barbosa \& Cía. S. en C.

Sentencia 20I4-80I-I66, Jovalco s.A.s. v. Construcciones Orbi S.A. 
Sentencia 20I4-80I-099, Luz Amparo Mancilla Castillo y Alfonso Bolívar Correa v. Handler s.A.s., Liliana Castillo Bautista, Omar Fernando Martínez Lozano y Edisson Emir Hernández.

Sentencia 20I4-80 I-50, Carlos Hakim Daccach v. Jorge Hakim Tawil, Alejandro Hakim Dow, Angélica Patricia de la Torre Gómez, José Alejandro Samper Carreño, Daniel Alfredo Materón Osorio, Jaime Cano Fernández, Luis Miguel García Peláez, José Mauricio Rodríguez Morales, Carlos Alberto Campos Murcia, Edduar Leonardo Flórez Bohórquez, Luis Fernando Amaya Mateus y Raquel Castillo González.

Sentencia 2014-800-52, Sucesión María del Pilar Luque de Schaefer v. Luque Torre Ltda. en liquidación.

Sentencia 20I4-800-29, Loyalty Marketing Services Colombia S.A.S. v. Shirley Natalia Ávila Barrios.

Sentencia 20I4-80I-I64, Jorge Eduardo Terrero Wilches v. Rafael Uribe Toro.

Sentencia 20I4-80I-I36 de la Superintendencia de Sociedades, Martha Cecilia López v. Comercializadora G.L. s.A.s., Luis Enrique Gil Builes y Distribuidora del Kamino s.A.s.

Sentencia 2014-800-52, Sucesión María del Pilar Luque de Schaefer v. Luque Torre Ltda. en liquidación.

Sentencia 20I3-80I-37, Proedinsa Calle \& Cía. S. en C. v. Colegio Gimnasio Vermont Medellín S.A.

Sentencia 20I3-80I-35, SAC Estructuras Metálicas S.A. v. Praxedis José Daniel Correa Senior, Santiago Francisco Correa Laverde y Gloria Estella Gallo Pérez.

Sentencia 20I3-80I-29, Juan Carlos Borrero Quintero v. Lupa Jurídica s.A.s.

Sentencia 20I3-80I-25, Francisco A. Martínez Quintero y Lucía Martínez de Kurday v. Sabajón Apolo S.A. y otros.

Sentencia 20I3-80I-I8, Hernando José Vergara Támara v. Hernando Vergara Támara y Cía. Ltda. 
Sentencia 20I 2-80I-029, Capital Airports Holding Company v. CAH Colombia S.A.

Sentencia del i I de marzo de 2004 de la Sala de Casación Civil de la Corte Suprema de Justicia, expediente 7582, M.P. José Fernando Ramírez Gómez.

\section{Normas}

\section{Colombia}

Constitución Política de Colombia.

Código de comercio (Dcto. Ley 4ro de I97I).

Código civil.

Decreto I074 de 2015.

Estatuto Tributario (Dcto. 624 de I989).

Ley 222 de 1995 .

Ley 79I de 2002.

Ley 964 de 2005 .

Ley 258 de 2008 .

Ley I 564 de 20 I 2 (código general del proceso).

Superintendencia de Sociedades, Oficios 220-069753 del 25 de mayo de 2015 , 220-0293I4 del i9 de marzo de 2013, 220-I40389 del 27 de noviembre de 2012 y $220-05$ I 693 del 26 de junio de 20 I 2.

\section{Estados Unidos}

Delaware General Corporation Law.

Restatement (Second) of Contracts.

Restatement of the Law of Restitution. 
Uniform Commercial Code.

\section{Francia}

Código de comercio.

\section{Reino Unido}

Foss v. Harbottle (1843) 67 ER i 89. 